\title{
A SERVICE-ORIENTED FRAMEWORK FOR INTERPERSONAL COMMUNICATION IN ARCHITECTURE, ENGINEERING AND CONSTRUCTION
}

\author{
Robert Klinc, Žiga Turk, Matevž, Dolenc
}

Subject review

In collaborative engineering environments communication and information sharing among participants is essential for successful project delivery. Modern information technology is driving the world towards two divergent communication topologies: 1) the industry is driven towards a centralized one around an information model, 2) citizens using information technologies at home are driven towards a meshed one where each can communicate whenever to whoever using communication services like those in social media. This paper presents the analysis, conceptual framework, architecture and prototype of a system that is bringing the latter to the engineering community. The framework consists of two main components: 1) a framework engine providing working environment and support for core services such as locale storage and module integration, and 2) external modules, extending core capabilities of the framework. For the purpose of this research work the SWOT analysis has been carried out revealing main characteristics of the proposed approach.

Keywords: communication in construction; decentralized information system; interpersonal communication network; service-oriented architecture

Uslužno orijentiran sustav za međuljudske komunikacije u arhitekturi, inženjerstvu i izgradnji

Pregledni članak

U suradničkim tehničkim okruženjima razmjena komunikacije i informacija među suradnicima je od bitne važnosti za uspješno izvršenje projekta Moderna informatička tehnologija vodi ka dvije divergentne komunikacijske topoligije: 1) industrija je usamjerena ka centralizaciji oko informatičkog modela, 2) građani, koji se informatičkom tehnologijom služe kod kuće, idu prema umrežavanju u kojem svatko može komunicirati sa svakim kad god hoće služeći se komunikacijskim uslugama poput onih u društvenim medijima. U radu se daje analiza, zamišljeni model, arhitektura i prototip sustava koji ove druge usmjerava prema inžinjerskoj zajednici. Model se sastoji od dvije glavne komponente: 1) pokretačkog dijela - motora koji osigurava radno okruženje i podršku ključnim uslugama kao što su lokalna pohrana i integracija modula, 2) vanjskih modula, koji proširuju ključne sposobnosti motora. U svrhu istraživanja provedena je SWOT analiza kojom su određene ključne karakteristike predloženog pristupa.

Ključne riječi: decentralizirani informacijski sustav; interpersonalna komunikacijska mreža; komunikacija u inženjerstvu; uslužno orijentirana arhitektura;

\section{Introduction}

The transition from traditional collaboration to a collaboration that is facilitated by digital information and communication technology is changing the paradigms of engineering communication networks, particularly their topology. On one hand, the transition from paper or digital document exchange towards the use of document management systems and building information models (BIM) is encouraging star shaped topologies, with the BIM (or document repository) in the centre. On the other hand, builders have traditionally interacted in a peer-topeer fashion where a fully interconnected communication graph emerged. Building professionals today communicate directly and on demand to each other even more, supporting the highly un-repetitive and often improvised nature of their profession. Such form of interaction flows is made much easier by the Internet based communication tools including those that support social media services. The two paradigms, centralised and meshed (or, in other words, decentralized), are radically different from each other; yet, they are both supposed to support the same processes.

Over the last decades the research regarding the communication and collaboration in construction has been focusing mainly on the structure of information and information needs of building processes. The communication between people has gained much less attention. As pointed out by Wilkinson [1] this can be problematic at least from the following: a) effective collaboration requires a combination of people, processes and technology/information, and b) successful collaboration is roughly $80 \%$ people and $20 \%$ technology/information. In addition, human related subjective factors together with organization culture and culture itself are usually neglected [2].

\subsection{Motivation}

Both academic as well as business environments have been trying to improve communication and collaboration among partners in construction projects for decades. Davidson and Moshini [3] argued that the efficient transfer of information could reduce the cost of construction by as much as $25 \%$. Although information and communication technologies (ICT) offer crucial benefits from the viewpoint of the communication and collaboration between people and working groups the architecture, engineering and construction (AEC) industry has not yet adapted to the requirements of the engineers and architects that would receive the needed information at the point of activity [3].

Predominant practice in the AEC industry is still the same as it was in the 1990s - the IT department provides a user with all the hardware and software equipment. The problem with this is that the IT departments in the AEC related companies cannot cope with the pace of the advancements in the technology and software. This is especially true for the small to medium sized enterprises (SME), typical for the AEC industry. Often, the services and even devices that employees use in their private lives are closer to the state of the art than what they use at work. 
Fortunately, the current trends in ICT are encouraging because they focus mainly on people and processes and less on technology and technical specifications, which seem to have reached a state where they are not a problem anymore. As majority of the newly emerged networks is closer to decentralized nature of the communication, the topology of the interaction between users fits perfectly to the traditional fully connected model of the construction project interaction that has been known for centuries.

On the other hand, custom-made construction collaboration technologies empowered star network model, building on the interaction through a single central hub [4]. While the star topology is considered the easiest topology to design and implement, its characteristics do not correspond well to the particularities of the successful human interaction or usual ways of working in the construction industry.

\subsection{Research objectives}

While most of the recent research regarding communication and/or collaboration in AEC has been focusing on the exchange of the structured information and data [5][6], this paper concentrates on the exchange of information (communication) among people. Motivated by the success of the state-of-the-art web technologies and wide adoption of the mobile consumer devices, main objective of this study is to conceptualize an informal, distributed ICT framework for effective, efficient and successful communication and collaboration among professionals in AEC, taking into account the particularities of the construction industry.

\subsection{About the paper}

The paper begins with the theoretical background of the communication and against this background analyses the interaction patterns and communication in the construction industry, particularly how it has been changing because of the new information and communication technologies (ICT). It identifies the schism between the centralized and the fully connected interaction model and claims that, in fact, the latter is the natural way in which builders have been communicating for centuries. That is why the new technology should support it rather than forcing the industry to change its ways of doing things because the development of centralized systems is easier. Authors of this paper believe that technologies behind social networks together with the rising technological awareness of the people as the result of the consumerisation of IT are providing the solution to that problem. Consequently, a new approach to the ICT enabled communication is presented with the help of the prototype, developed to illustrate the soundness of the concept.

\section{Background}

One of the essential skills of the AEC professionals is the ability to express them clearly and concisely or in other words - to communicate efficiently and effectively. What is more, communication is arguably the most important aspect of project management since without the effective communication between the participants the AEC project cannot be finished successfully (e.g. on time and within budget). What makes communication in the AEC different compared to other engineering domains is the fact that construction projects are conducted in a dynamic social system where nothing is particularly stable for a very long time [7].

Among key issues for successful communication and collaboration within the industry is fragmentation [8]. The source of the fragmentation lies in the fact that majority of the AEC enterprises in the European Union (EU) serve a local market, therefore the whole sector is characterised by a relatively high number of small enterprises and small number of large ones [9]. Although the EU construction sector is encompassing more than 2,4 million enterprises [10], figures show that $41,5 \%$ of the EU-27 construction workforce in 2006 was employed in the enterprises with 1 to 9 employees and $72,1 \%$ in the enterprises with less than 50 employees [9]. When looking at the small markets it can be seen that the AEC sector can be even more granular - there were $93,2 \%$ of the AEC enterprises in Slovenia with 0 to 9 employees, 58,2\% among them only have 0 or 1 employee ( 0 means that the enterprise represents 1 self-employed person) [11]. The situation outside the EU is comparable. According to statistics from 2008 [12] there are 8,4\% of AEC enterprises in the USA that have 20 to 99 employees, $1,1 \%$ have 100 to 499 and only $0,1 \%$ have 500 or more employees. That leaves $90,4 \%$ of the enterprises in the USA with 0 to 19 employees. In Australia, for example, there is an overwhelming majority of micro-businesses with $94 \%$ of enterprises employing less than 5 people and less than 1 $\%$ of them employing 20 people or more [13]. Speaking of EU, the recession made things even worse.

As IT represents a substantial investment for most corporations [14], it is clear why AEC enterprises with less than 10 employees are not able to continually invest into latest technology. Micro companies together with small to medium sized enterprises (SME) are the slowest to engage the IT. Since they comprise the majority of the AEC sector and, as Turk [15] pointed out, partners with different levels of IT literacy in construction process often settle for the lowest common denominator, it is not surprising that IT adoption in AEC industry is relatively poor.

Tenah [16] illustrated that some construction companies buy packaged information systems without examining the functions and information needs of their personnel. Instead of adapting such packaged information systems to the needs of their employees, the real world scenario is directly the opposite - employees have to adapt to the system. As a consequence, information system's adoption is poor despite the high investment and potential benefits.

\subsection{Communication}

Dainty et al. [17] noted that the point of communication in most cases is that one person wishes another to receive information. Despite numerous definitions most of the engineering literature suggests that communication is essentially about the transfer of information between people $[1,7,17]$. On the other hand, social studies literature defines communication as sharing of meaning to reach a mutual understanding and to gain response and action. This usually involves some form of 
interaction between the sender and the receiver of the message [7].

Looking at the communication through the lens of the evolution of the connectivity of nodes in communication network, the development of the information and communication technologies resulted in the change from centralized to more decentralized, fully connected network topology (see Fig. 1).

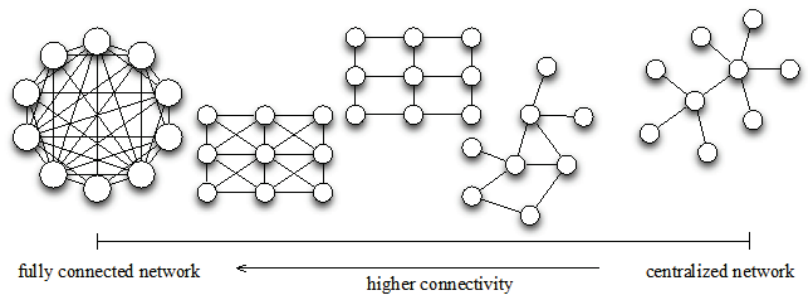

Figure 1 Network topology based on connectivity.

\subsection{Communication in construction}

During the transition from traditional to ICT supported communication, the method of interaction between people changed. From the fully connected communication network topology where every person could talk to another directly the topology changed to the centralized one [1], forcing members of communication process to communicate through an intermediary (see Fig. 2).

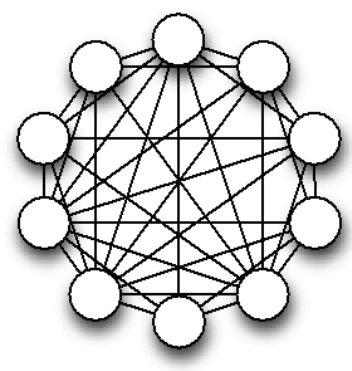

traditional

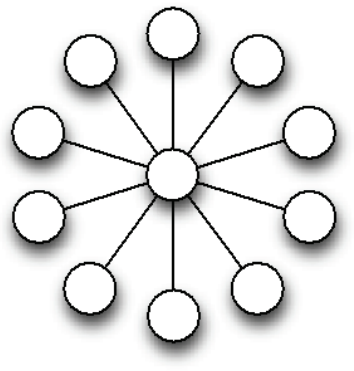

ICT supported
Figure 2 Diagram of possible interactions in a construction working group

The majority of the tools supporting communication and collaboration today enable one-time and just-in-case communication, but lack stronger, systematic and structured support for just-in-time connections. Most of the emerging problems are still solved traditionally, usually by phone, in the form of informal communication. Kraut et al. [18] argue that informal communication is an important mechanism that helps all members of a project to achieve both production and social goals of a team. Informal communication is spontaneous, interactive and rich. That is why it is important to address the challenge of supporting informal communication with the use of $\mathrm{I}(\mathrm{C}) \mathrm{T}$ in order to provide additional channel for successful collaboration among different AEC project partners.

\subsection{Consumerization of IT}

The term "consumerization of IT" was defined by Moschella et al. [19] and is used to describe a powerful trend of using consumer devices and underlying infrastructure for both personal and consequently professional tasks. With the generations of people becoming more and more technology-savvy together with consumer devices and services improving significantly in terms of their functionality and ease of use, this trend has a tremendous impact on the transformation of the traditional enterprise infrastructures.

The adoption of consumer technologies within the enterprise is growing rapidly [20]. Even though most of the initial momentum comes from the end users that would like to bring the innovative, simple-to-use services known from their personal life to their working environment, the growing tension between the traditional deploying models and consumerized alternatives is forcing enterprises to adapt. The trend fits well into the idea of ubiquitous computing where the computing elements, services and their inter-communication are largely hidden from the user [21], focusing on the usage rather than on the technology.

For AEC industry, the process of consumerization of IT will be difficult to manage as it disrupts most of the practices used till date, especially from the security point of view.

\subsection{The concept of centralization and decentralization of information systems}

Business information systems of today have to be much more dynamic and adaptive than in the past in order to ensure competitiveness to companies that use them [22]. During the last decades, two main information system architectures evolved - centralized and decentralized [23]. Even though Bacon [24] divided the subject to two areas: a) hardware and software, and b) organization and management, it is difficult to draw the line between technological and organizational aspects of the two concepts.

According to Allen and Boynton [22], following the centralized approach results in the core parts of the information system and business activities are being centralized, built around central data collections, common business practices and common application systems. Technically speaking, a completely centralized information system handles all processing at a single point, has centralized development of applications and provides central technical services. Among the key strengths of this approach are the integration, flexibility and ease of introducing management strategies. The concept also brings some weaknesses as such system is expensive, has long development cycles, is prone to organizational politics and can lock the organization into an inflexible and inefficient (fixed and solid) structure. Another concern is the limited possibility of end-users to have an impact on the developed components [23].

On the other hand, a completely decentralized system may have no central control of system development. Hugoson [23] argues that each component of the decentralized structure must fulfil specified demands for interaction with other components; nevertheless it should provide means to develop, maintain and change inner structure in each system component without dependencies to other systems, as long as the specified interaction stands. The development, maintenance and management of the system are dispersed as far down in the organization as possible, tying various parts together with 
inter-linked communication and a philosophy of full access to information [22]. The information systems of that type are suitable for fast changing technologies, are innovative, effective and efficient. Unfortunately, the decentralized approach can end up in a number of separate systems with unclear responsibilities, with inconsistencies and without computerized interaction [23].

\section{Design of the framework}

In order to develop a framework that would result in the ICT system targeting the particularities of the AEC industry and meeting the expectations of the end-users, the prototyping approach to the system development had been used. It was chosen in order to significantly shorten the time from the idea to the useful prototype that can be evaluated. Instead, the design was merged with the development process, focusing on the prototype and its compliance to the initial requirements of the end-users.

The designed and developed prototype is filling the gap between the traditional information and communication systems used in the business environment today and the modern, simple, intuitive information and communication services used at home, usually for communication between friends and family. The idea was built on the grounds of the Enterprise 2.0 initiative that followed the latest findings regarding technology populism and social interaction.

The advantage is that users are not forced into using any of the services or tools they do not know or they are not willing to use. As reported before [25], that can also be one of the barriers for successful adoption of the disruptive technology.

\subsection{Basic requirements}

Prior to developing an ICT system the system and design requirements traditionally have to be identified in order to ensure the efficiency and usability of the developed system.

The main sources of information from which the general end-user requirements were derived were the latest findings regarding the behaviour of the knowledge workers [20, 26, 27, 28]. Findings coincide well with the requirements for mobile computing applications for construction that are threefold: information sufficiency, fast communication and advantageous visualization [29].

From the engineering collaboration and communication perspective, the end-user requirements for the successful collaborative environment were derived from the past EU projects OSMOS [30], GLOBEMEN [31], IST for CE [32] and InteliGrid [33]. They can be summarized as "5S" requirements [33]: (1) security, (2) simplicity, (3) stability \& standards, (4) scalable service orientation, and (5) semantics.

The result was a design of decentralized system architecture that lead to the prototype.

\subsection{Framework architecture}

The framework was designed as a decentralized (distributed) ICT system for communication and collaboration in construction teams addressing the problem of interpersonal and small-group communication. As it was designed without the solid structure, regulated processes or designated data, it should be considered as an informal information system. The main reason for choosing the decentralized system instead of the widely used centralized one was the good agreement between the selected design and the topology of the nodes in the communication network.

Due to the prototyping approach to the development the resulting framework has characteristics of both centralized and decentralized information systems and is therefore hybrid. Conceptually, the architecture of the framework is the classic three-tier client-server architecture (see Fig. 3), which introduces a general separation of three parts: client tier (also named presentation layer or, more specifically, user interface), middle tier (also named application layer) and data storage tier (also database layer). Database layer represents the storage for the heterogeneous, unstructured and otherwise independent data and information pieces. On the other hand, the presentation layer is used to display these pieces to the user in a more structured way. The important tasks are done in the application layer. In this layer, all of the services allowing engineers to successfully communicate and collaborate with each other are integrated, adding value to the otherwise dispersed messages.

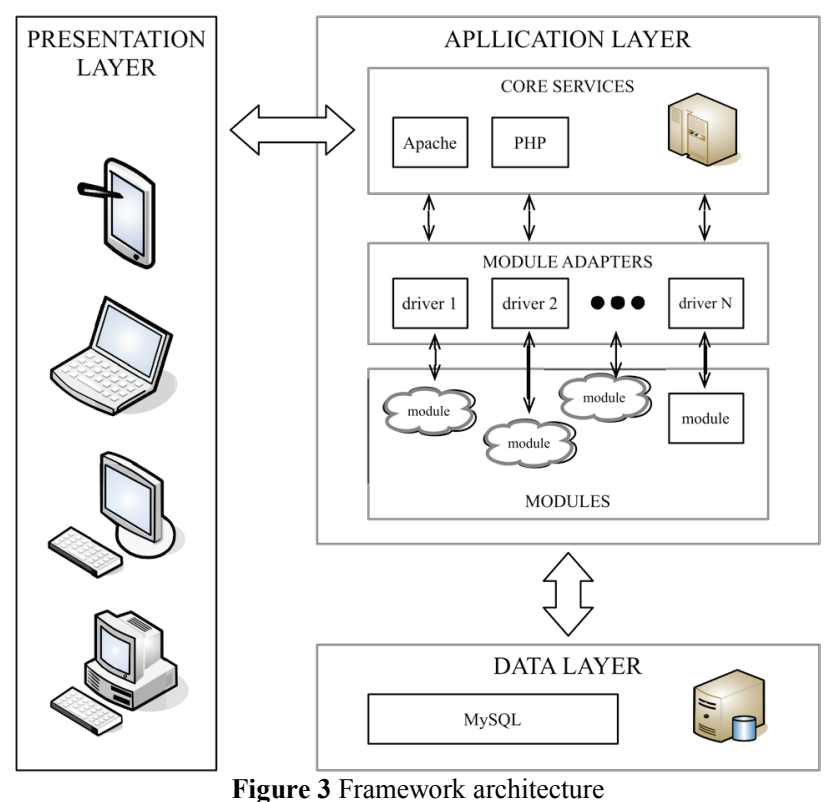

In order to integrate heterogeneous and otherwise independent services, the principles of service-oriented architecture (SOA) have been applied. Fortunately, concept of SOA coincides well with the nature of decentralized systems.

Due to the service-oriented architecture of the proposed framework it is possible to develop and include various framework modules. To make the system extensible, scalable and portable the functions of the implemented modules have to be separated from the business logic of the whole system - the business logic is therefore divided to each individual module that has to follow the schema of the data layer. 
In order to fit the module into the system, a set of configuration files have to be prepared. The implemented modules can fill the gap from every aspect of the system's business layer - from the change of the authentication protocol to the implementation of new channels for communication.

\section{Prototype framework}

The prototype presents a central point of access to the distributed data of the distributed heterogeneous (Web) services. The individual parts of the system are loosely coupled while the communication is realized through various communication protocols (HTTP, POP3 \& SOAP).

\subsection{Implemented framework architecture}

The implemented framework architecture consists of a number of smaller tiers on the level of business logic and data storage. The result is a complex three-tier architecture with loosely coupled components and modules.

The user interacts with the system using preferred Internet browser. Presentation layer of the proposed framework system is therefore presented by (X)HTML output. Consequently, the developed prototype is accessible with any device capable of accessing Internet services, including computers, laptops, netbooks, mobile/smart phones etc.

The application layer tasks are performed by the web server [34] that resides on the Linux operating system [35]. Output of presentation layer is handled with PHP [36] scripting language. To improve end-user experience, Ajax web development technologies and techniques were used.
The data layer is divided to several parts. While the core framework relies on the data server, fitted with relational database [37](see Fig. 4), the loosely coupled framework modules have their data stored in the cloud, accessing them through the data layer performing remote calls.

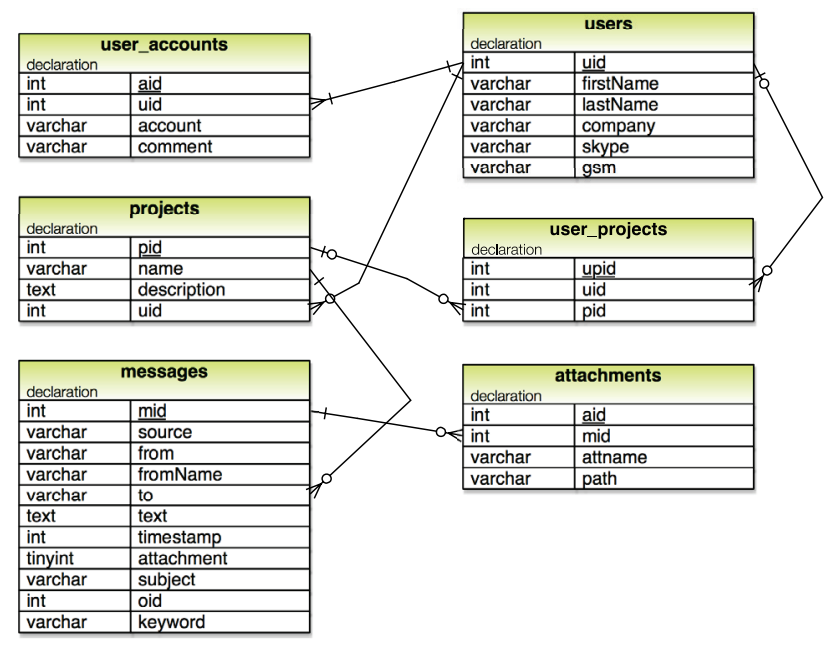

Figure 4 ER database model of the framework core.

Despite the fact that the developed prototype follows some of the characteristics of the centralized systems, its components are independent and individually represent a single node in the fully connected topology of the communication paths among end-users. Decentralized system components are loosely coupled and communicate via messages in different formats (XML, JSON, plain text). The communication between users using services managed by service providers remains intact (see Fig. 5).

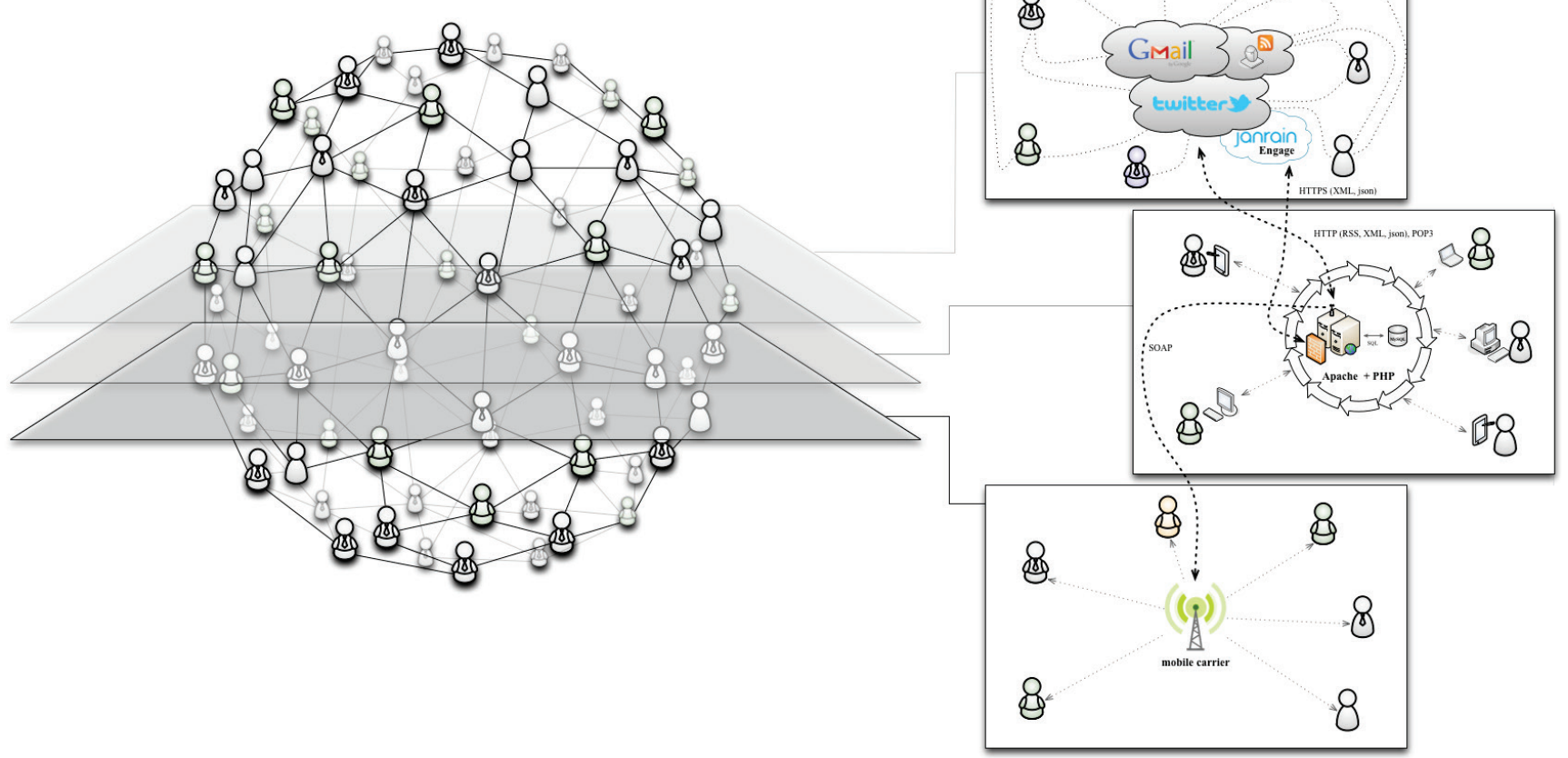

Figure 5 Schematic view of the prototype architecture 


\subsection{Implemented framework modules}

In order to extend the capabilities of the prototype several framework modules have been developed and implemented, demonstrating the versatility of the serviceoriented architecture as well as the scalability of the proposed design.

User authentication. Web services and web applications in general use authentication based on the authentication pair username/password, stored in the database server - username is usually stored in a plain text format, on the other hand, password has to be encrypted. While the storage of secure and sensitive data is one problem, the other problem is the number of the authentication pairs that a person has to remember and the number is growing exponentially. To avoid such issues the use of solutions based on open standards regarding decentralized authentication such as OpenID [38] and OAuth 2.0 [39].

The authentication procedure is performed outside our prototype in the cloud maintained by external partners. Prototype is using authentication based on the web service Janrain Engage [40] which uses authentication mechanisms of the external services for the purpose of the user identification. It acts as a proxy between our framework and external identity providers.

Email module. Email is still a dominant method of exchanging information among business professionals. That is why the framework has to be able to retrieve email messages, tag them and store them for future reuse. The developed email module is the autonomous service for the email access using Post Office Protocol version 3 (POP3) or Internet Message Access Protocol (IMAP) providing the ability to access any email provider. The developed module is capable of dealing with attachments, tagging emails and assigning them to appropriate projects and authors.

RSS module. As a format for delivering regularly changing web content based on a XML syntax, the RSS module adds the ability to retrieve the latest content from the various web sources (such as web sites, blogs, discussion groups and communities of interests) to the system. Framework module for collection of content in RSS form is capable of collecting data from wide variety of RSS sources as long as the source is in one of the standardized supported forms. When content source is accessed, the content is analyzed, parsed, assigned to project and stored into the database.

Short messages (SMS) module. AEC industry has been known for its wide adoption of mobile phones, therefore a module capable of communicating through devices every professional has always present in any location is needed. The developed module acts as a notification method for the users that can be notified of any change within the project. It uses web service of the national mobile provider that allows us to send messages using SOAP protocol. It is the only service within our prototype that is not free of charge.

Social networking module. Since social networking sites attracted a lot of users in recent years and are becoming one of the most popular methods for interpersonal communication, the framework should provide the ability to communicate through one or more popular social networking services. For the prototype, the module accessing the Twitter service [41] has been developed. It is extracting the exchanged messages across working group network, tags them (messages are assigned to different projects according to hashtags used) and stores them in the database server for future reuse. Original message paths remain unaffected.

The outputs of these modules are converged into the framework relational database thus not affecting the topology of the original network, adding additional layer of the communication topology instead.

\subsection{System tests}

A series of small tests in the test group has been performed. The preliminary tests show a considerable potential for the integration of the introduced prototype into the social network of the VO users. Its main advantage is the ability of integration into the working environment without specific adaptation. This results in the unaltered working tools, processes and services as well as high labour utilisation.

Despite numerous advantages of using the prototype there has been a number of concerns reported. That is why a SWOT analysis of the proposed system has been performed.

\subsection{SWOT analysis of the proposed system}

A SWOT analysis was carried out using findings from the literature and results of the on-line questionnaire sent out to the domain professionals in order to analyze the strengths, weaknesses, opportunities and threats of the suggested approach.

Table 1 SWOT analysis of the developed AEC communication 2.0

\begin{tabular}{|c|c|}
\hline STRENGTHS & WEAKNESSES \\
\hline $\begin{array}{ll}\text { - } & \text { modular design } \\
\text { - } & \text { implicity } \\
\text { - } & \text { low entry cost } \\
\text { support for informal } \\
\text { comunication } \\
\text { - } & \begin{array}{l}\text { adaptable to current working } \\
\text { practices }\end{array} \\
\text { - } & \text { support for user enthusiasm }\end{array}$ & $\begin{array}{ll}\text { - } & \text { depends on ICT literacy and } \\
\text { user enthusiasm } \\
\text { - } & \begin{array}{l}\text { depends on external web } \\
\text { services }\end{array} \\
\text { - } & \begin{array}{l}\text { no support for structured } \\
\text { engineering data }\end{array} \\
\text { - } \quad \text { informal system }\end{array}$ \\
\hline OPPORTUNITIES & THREATS \\
\hline $\begin{array}{ll}- & \text { fast sharing of data and } \\
\text { information from the point } \\
\text { of activity } \\
\text { - } \\
\text { additional layer of data } \\
\text { storage } \\
\text { support for modern } \\
\text { consumer devices }\end{array}$ & $\begin{array}{ll}\text { - } & \text { lack of knowledge and } \\
\text { enthusiasm of end users } \\
\text { - } \\
\text { no objective methodology } \\
\text { for measuring benefits } \\
\text { - } \quad \text { no explicit relationship } \\
\text { specific legal coverage }\end{array}$ \\
\hline
\end{tabular}

The methodology for the on-line questionnaire was selected considering the experiences from the similar research [42] that despite heavy engagement and advertising produced low number of quality responses. That is why it was decided to use the snowballing sampling technique, a non-probability sampling where first round of surveyed people were asked to pass the questionnaire to co-workers, friends and acquaintances from the AEC profession in order for the sample to build up and the volume of data is enough for the results to become useful. Invitations were sent to the group of 29 
people with the request to pass the questionnaire on. In the end, 52 responses were received. Results are summarized in Tab. 1.

\section{Discussion and conclusions}

The presented communication system architecture and the developed prototype are oriented towards successful communication among participants in the construction projects. It can be concluded that freely available cloud based services known from the home environment can be used in the business environment and are especially suitable for the hectic and fragmented industries with different levels of IT literacy such as AEC. Independent nature of the services loosely tied into the service-oriented architecture of the system resulted in the flexibility, adaptability and scalability of the whole system. With the use it also became apparent that the best results are achieved using standardized technologies such as RSS and email, while less standard approaches using application programming interfaces (API) of the services occasionally malfunctioned. The reason can be found in the lack of the contractual obligations with the service providers, as all of the used services are available free of charge.

There are also open issues regarding security. For decades AEC companies have been working hard to keep control over data and information as they were considered the main advantage over competitors. That is why it is quite a daunting task for the industry to adopt the paradigm brought on the table by the cloud computing. Nevertheless, as today is almost impossible to keep the information inside the borders of the company intranet, AEC companies of the future will have to focus on maintaining a thin layer above the cloud computing services that were established and are maintained by others instead of building core computer infrastructures. The consequence will be that the security in today's sense will inevitably have to be replaced by trust. Businesses will have to have confidence in service providers that they are able to ensure data confidentiality, integrity and availability [43]. Consequently, contractual obligations between a service provider and a business consumer known today will have to change accordingly [44].

While the use of flexible communication tools relying on social networking infrastructure has proven extremely useful, future work should address the weaknesses and threats from our analysis.

The users of the proposed system would benefit from the general knowledge of IT, particularly the social networking tools and from the general trend of consumerisation of IT. Dependence on external Web services is both a strength and weakness. It is a strength as it reduces the need of in-house IT investment and maintenance. Over the years it became more clear which of these external web services are surviving and which were just an interesting concept. In addition, the related concerns about privacy, ownership of information etc. have been addressed by more precise user agreements available for these services. Should all this be insufficient, there are a number of open-source applications available that have similar functionality and can be deployed locally. The support for structured engineering data and BIM is indeed not available, however, as BIM tools are opening to social networking, this can be overcome without changing the architecture. There is also a significant amount of information and communication that will, for quite some time, continue to be managed outside or on the side of BIM systems. In this context our system provides an umbrella for that. Informality and flexibility becomes a strength and both systems become complementary.

As far as threats are concerned, lack of enthusiasm is a threat for any technology, however, services that address needs do not require enthusiasm to be implemented. As people are enthusiastically using meshed social approaches for non-professional purposes this threat is not very realistic. As with many information technologies it may be difficult to prove to the management upfront the benefits of this technology. But the investment is much smaller and risks of failure minor so that the case for use could be made as project progresses. The nature of solutions is also such that it can be implemented as a pilot in just one of the firm's activities. Specifics of the legal consequences need further study, it is likely, however, that a digital collaboration in general requires some kind of legal agreement. The problem is not isolated to this system.

Further research should focus on testing some claims made above - development should focus on accommodating this approach with information exchanges where (at least partly) centralized approaches have proven useful as well. This would be allowing the industry to benefit from the best of both worlds.

\section{References}

[1] Wilkinson, P. Construction Collaboration Technologies: The extranet revolution, Taylor \& Francis, GB, 2005.

[2] Xue, X.; Shen, Q.; Fan, H.; Li, H.; Fan, S. IT supported collaborative work in $\mathrm{A} / \mathrm{E} / \mathrm{C}$ projects: A ten-year review. // Automat. Constr. 21, (2012), pp. 1-9. DOI: 10.1016/j.autcon.2011.05.016

[3] Bowden, S. L. Application of mobile IT in construction, Doctoral dissertation, Loughborough University, Centre for Innovative and Collaborative Engineering (CICE), $171 \mathrm{p}$.

[4] Chassiakos, A. P. A web-based system for managing construction information. // Advances in Engineering Software. 39, 11(2008), pp. 865-876. DOI: 10.1016/j.advengsoft.2008.05.006

[5] Pazlar, T.; Turk, Ž. Interoperability in practice: geometric data exchange using the IFC standard. // ITcon Vol. 13, Special Issue Case studies of BIM use, pp. 362-380, http://www.itcon.org/2008/24 (last access: 21.12.2014)

[6] Cerovšek, T. A review and outlook for a Building Information Model (BIM): A multi-standpoint framework for technological development. // Advanced Engineering Informatics. 25, (2011) pp. 224-244. DOI: 10.1016/j.aei.2010.06.003

[7] Emmit, S.; Gorse, C. Communication in Construction Teams, Taylor \& Francis, New York, USA, 2007.

[8] Brewer, G.; Gajendran, T. Emerging ICT trends in construction project teams: a Delphi survey. // ITcon Vol. 14, Special Issue Technology Strategies for Collaborative Working, pg. 81-97, 2009, http://www.itcon.org/2009/09 (last access: 20.12.2014)

[9] Stawinska, A. The EU-27 construction sector: from boom to gloom, Eurostat - Statistics in focus, ISSN 1977-0316, http://ec.europa.eu/eurostat/documents/3433488/5564584/K S-SF-10-007-EN.PDF/e96cf22c-d9e9-4ef3-8e8ee53cd940d8e1?version=1.0 (last access: 12.01 .2015$)$

[10] Goulding, J.; Nadimb, W.; Petridis, P.; Alshawi, M. Construction industry offsite production: A virtual reality 
interactive training environment prototype, Advanced Engineering Informatics 26 (2012), pp. 103-116. DOI: 10.1016/j.aei.2011.09.004

[11] Statistical Office of the Republic of Slovenia, Statistical yearbook 2009, http://www.stat.si/eng/index.asp (last access: 29.02 .2012$)$

[12] U. S. Census Bureau, http://www.census.gov/, http://www.census.gov/epcd/susb/latest/us/US--.HTM (last access: 12.01 .2015$)$

[13] Love, P. E. D.; Irani, Z.; Edwards, D. J. Industry-centric benchmarking of information technology benefits, costs and risks for small-to-medium sized enterprises in construction. // Automation in Construction. 13, (2004), pp. 507-524. DOI: 10.1016/j.autcon.2004.02.002

[14] Agarwaland, R.; Karahanna, E. Time Flies When You're Having Fun: Cognitive Absorption and Beliefs about Information Technology Usage. // MIS Quaterly. 24, 4(2000), pp. 665-694. DOI: 10.2307/3250951

[15] Turk, Ž. Construction informatics: Definition and ontology. // Advanced Engineering Informatics. 20, (2006), pp. 187199. DOI: 10.1016/j.aei.2005.10.002

[16] Tenah, K. A. Construction personnel role and information needs. // Journal of Construction Engineering and Management. 112, (1986), pp. 33-48. DOl: 10.1061/(ASCE)0733-9364(1986)112:1(33)

[17] Dainty, A.; Moore, D; Murray, M. Communication in Construction: Theory and practice, Taylor \& Francis, London, UK, 2006. DOI: 10.4324/9780203358641

[18] Kraut, R. E.; Fish, R. S.; Root, R. W.; Chalfonte, B. L. Informal Communication in Organisations: Form, Function, and Technology. // in: Oskamp, S.; Spacapan, S. (editors.), Human Reactions to Technology: The Claremont Symposium on Applied Social Psychology, Sage Publications, Beverly Hills, (1990), pp. 145-199.

[19] Moschella, D.; Neal, D.; Opperman, P.; Taylor, J. The Consumerization of Information Technology, Position paper, CSC's Leading Edge Forum, 2004.

[20] Del Prete, C.; Levitas, D.; Grieser, T.; Turner, M. J.; Pucciarelli, J.; Hudson, S. IT Consumers Transform the Enterprise: Are You Ready? // An IDC White Paper sponsored by CA Technologies, 2011 (available on-line http://www.ca.com/ /media/Files/whitepapers/signatureresearch-idc-whitepaper-final.pdf, last access: 12.01.2015)

[21] Prekop, P.; Burnett, M. Activities, context and ubiquitous computing. // Computer Communications. 26, (2003), pp. 1168-1176. DOI: 10.1016/S0140-3664(02)00251-7

[22] Allen, B. R.; Boynton, A. C. Information Architecture: In Search of Efficient Flexibility. // MIS Quarterly. 15, 4(1991), pp. 435-445. DOI: 10.2307/249447

[23] Hugoson, M. A. Centralized versus Decentralized Information Systems: A Historical Flashback. // In: History of Nordic computing, Springer. (2009), pp. 106-115. DOl: 10.1007/978-3-642-03757-3 11

[24] Bacon, C. J. Organizational Principles of Systems Decentralization. // Journal of Information Technology. 5, (1990), pp. 84-93. DOI: 10.1057/jit.1990.17

[25] Rebolj, D.; Čuš Babič, N.; Magdič, A.; Podbreznik, P.; Pšunder, M. Automated construction activity monitoring system. // Advanced Engineering Informatics. 22, (2008), pp. 493-503. DOI: 10.1016/j.aei.2008.06.002

[26] McAfee, A. Enterprise 2.0: The Dawn of Emergent Collaboration. // MIT Sloan Management Review. 47, 3(2006), p. 2128. DOI: 10.1109/emr.2006.261380

[27] Trend Micro, Managing and Securing Consumerized Enterprise IT, A Trend Micro White Paper, 2011, http://www.trendmicro.co.uk/media/wp/consumerizationof-it-whitepaper-en.pdf (last access: 12.01.2015)

[28] Gens, F.; Levitas, D.; Segal, R. Consumerization of IT Study: Closing the Consumerization Gap, IDC iView 2011 study, 2011. http://www.achab.it/Download/kaseya/Doc/ IDC_Consumerization.pdf (last access: 12.01.2015)

[29] Kim, C.; Park, T.; Limb, H.; Kim, H. On-site construction management using mobile computing technology. // Automation in Construction. 35, (2013), pp. 415-423. DOI: 10.1016/j.autcon.2013.05.027

[30] Wilson, I.; Harvey, S.; Vankeisbelck, R.; Kazi, A. S. Enabling the construction virtual enterprise: the OSMOS approach. // ITcon Vol. 6, Special Issue Information and Communication Technology Advances in the European Construction Industry, pp. 83-110, 2001, http://www.itcon.org/2001/8 (last access: 12.01.2015)

[31] GLOBEMEN, Global engineering and manufacturing in enterprise networks, Proceedings of the GLOBEMEN conference, Helsinki and Espoo, Finland, 10-12 December 2002, http://cic.vtt.fi/projects/globemen/book/ (last access: 12.01.2015)

[32] Katranuschkov, P.; Scherer, R. J.; Turk, Ž. Intelligent services and tools for concurrent engineering: An approach towards the next generation of collaboration platforms. // ITcon Vol. 6, Special Issue Information and Communication Technology Advances in the European Construction Industry, pp. 111-128, 2001, http://www.itcon.org/2001/9 (last access: 12.01.2015)

[33] Dolenc, M.; Katranuschkov, P.; Gehre, A.; Kurowski, K; Turk, Ž. The InteliGrid platform for virtual organisations interoperability. // ITcon Vol. 12, pg. 459-477, http://www.itcon.org/2007/30 (last access: 12.01.2015)

[34] Apache HTTP server, http://httpd.apache.org/ (last access: 12.01.2015)

[35] Ubuntu web server, http://www.ubuntu.com/(last access: 12.01.2015)

[36] PHP: Hypertext Preprocessor, http://www.php.net/ (last access: 12.01.2015)

[37] MySQL, http://www.mysql.com/ (last access: 12.01.2015)

[38] OpenID Authentication $2.0 \quad$ - $\quad$ Final, http://openid.net/specs/openid-authentication-2_0.html (last access: 12.01.2015)

[39] The OAuth 2.0 Authorization Framework, http://tools.ietf.org/pdf/rfc6749.pdf (last access: 12.01.2015)

[40] Janrain Engage, http://www.janrain.com/products/engage (last access: 29.02.2012)

[41] Twitter, https://twitter.com/about (last access:12.01.2015)

[42] Pazlar, T.; Dolenc, M.; Duhovnik, J. The prodAEC benchmarking service results on the implementation of the information and communication technologies in the architecture, engineering and construction in Slovenia. // Gradbeni vestnik. 53, (2004), pp. 223-229.

[43] Kaufman, L. M. Data security in the world of cloud computing,security and privacy. // IEEE. 7, 4(2009), pp. 61-64.

[44] Klinc, R.; Dolenc, M.; Turk, Ž. Engineering collaboration 2.0: requirements and expectations. // ITcon Vol. 14, Special Issue Next Generation Construction IT: Technology Foresight, Future Studies, Roadmapping, and Scenario Planning, pg. 473-488,http://www.itcon.org/2009/31 (last access: 12.01 .2015$)$

\section{Authors' addresses}

\section{Robert Klinc, PhD} prof. Žiga Turk, PhD

Matevž Dolenc, $P h D$

University of Ljubljana, Faculty of Civil and Geodetic

Engineering, Jamova 2, 1000 Ljubljana, Slovenia

E-mail: rklinc@itc.fgg.uni-lj.si

E-mail: ziga.turk@fgg.uni-lj.si

E-mail: mdolenc@itc.fgg.uni-lj.si 